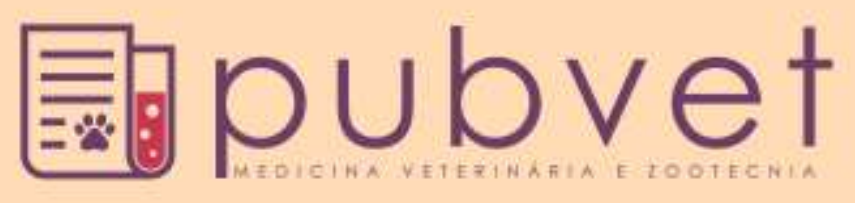

https://doi.org/10.22256/pubvet.v12n1a20.1-12

\title{
Ajuste dos níveis de energia e proteína e suas relações para galinhas poedeiras em diferentes condições térmicas
}

\author{
Marcelo Helder Medeiros Santana ${ }^{6} 1^{*}$, Edilson Paes Saraiva ${ }^{\natural}$, Fernando Guilherme \\ Perazzo Costa ${ }^{2}$, Jalceyr Pessoa Figueiredo Júnior ${ }^{3}$, Ana Maria Medeiros de \\ Albuquerque Santana ${ }^{4}$, Aldivan Rodrigues Alves $\$ 5$
}

${ }^{1}$ Professor de Zootecnia do Instituto Federal do Acre, Campus Sena Madureira, Sena Madureira - AC, Brasil.

${ }^{2}$ Professores de Zootecnia da Universidade Federal da Paraíba, Centro de Ciências Agrárias, Campus II, Areia-PB, Brasil-e-mail: ${ }^{3} Z$ Zootecnista da Secretaria de Estado de Agropecuária, SEAP-AC, Rio Branco-AC, Brasil.

${ }^{4}$ Licenciada em Ciências Biológicas - Secretaria Municipal de Educação, Sena Madureira-AC, Brasil.

${ }^{5}$ Professor de Zootecnia do Instituto Federal do Maranhão, Campus Caxias, Caxias-MA, Brasil.E-mail: aldivan.alves@ifma.edu.br *Autor para correspondência, E-mail: marcelo.santana@ifac.edu.br

\begin{abstract}
RESUMO. A adequação das dietas de galinhas poedeiras pode-se tornar uma estratégia essencial para a manutenção dos níveis produtivos das atuais linhagens do mercado. Tendo em vista que os custos com alimentação são os que mais oneram a atividade da avicultura de postura, ajustar principalmente os níveis de energia e proteína das dietas de galinhas poedeiras garante a integridade da qualidade dos ovos, melhoram a qualidade do ambiente e reduzem os custos inerentes à alimentação. Aves adultas mantêm seu conforto térmico com temperaturas entre 18 e $28^{\circ} \mathrm{C}$ e, tanto oscilações superiores (estresse por calor) ou oscilações inferiores (estresse por frio) são responsáveis por alterações no consumo de alimentos pelos animais, na tentativa de manter a temperatura corporal constante. Em situações de frio as aves aumentam o consumo de ração, na tentativa de produzir calor metabólico e manter a homeotermia. Já no calor, as aves reduzem o consumo de ração e aumentam o consumo de água, reduzindo a produção de calor endógeno e resfriando o corpo pelo gradiente entre a temperatura da água e do núcleo corporal das aves. Mesmo conhecido este mecanismo de ajuste no consumo de alimentos, observa-se que existem poucos relatos científicos acerca da razão energia:proteína em dietas de galinhas poedeiras, sendo assim, o objetivo central desta revisão.
\end{abstract}

Palavras chave: Estresse por calor, gorduras, produção de ovos

\section{Adjusting energy and protein levels and their relationships for laying hens in different thermal conditions}

ABSTRACT. The adequacy of laying hens diets can become an essential strategy for the
maintenance of the productive levels of the current lineages of the market. Considering that
feed costs are the ones that most affect poultry activity, adjusting the energy and protein
levels of laying hens diets ensure egg quality integrity, improves the quality of the
environment and reduces costs inherent of food. Adult poultry maintain their thermal
comfort with temperatures between 18 and $28^{\circ} \mathrm{C}$ and, either higher oscillations (heat stress)
or lower oscillations (cold stress), are responsible for changes in food consumption by the
animals, in an attempt to maintain a constant body temperature. In cold situations birds
increase feed intake, in an attempt to produce metabolic heat and maintain homeothermia.
In the heat, birds reduce feed intake and increase water consumption, reducing endogenous
heat production and cooling the body through the gradient between water temperature and
bird's body core. Although this mechanism of adjustment in food consumption is well 
known, it is observed that there are few scientific reports about the energy: protein ratio in laying hens diets, and thus, the main objective of this review.

Keywords: Heat stress, fat, egg production

\section{Ajuste de los niveles de energía y proteína y sus relaciones para gallinas ponedoras en diferentes condiciones térmicas}

RESUMEN: La adecuación de las dietas de gallinas ponedoras puede convertirse en una estrategia esencial para el mantenimiento de los niveles productivos de los actuales linajes del mercado. En vista de que los costos de alimentación son los que más afectan a la actividad de la avicultura de postura, ajustar principalmente los niveles de energía y proteína de las dietas de gallinas ponedoras garantizan la integridad de la calidad de los huevos, mejoran la calidad del ambiente y reducen los costos de la alimentación. Las aves adultas mantienen su confort térmico con temperaturas entre 18 y $28^{\circ} \mathrm{C}$ y, tanto las oscilaciones superiores (estrés por calor) o las oscilaciones inferiores (estrés por frío), son responsables de cambios en el consumo de alimentos por los animales, en el intento de mantener la temperatura corporal constante. En situaciones de frío las aves aumentan el consumo de alimento, en el intento de producir calor metabólico y mantener la homeotermia. En el calor, las aves reducen el consumo de alimento y aumentan el consumo de agua, reduciendo la producción de calor endógeno y enfriando el cuerpo a través del gradiente entre la temperatura del agua y del núcleo corporal de las aves. A pesar de ser bastante conocido este mecanismo de ajuste en el consumo de alimentos, se observa que hay pocos relatos científicos acerca de la relación energía: proteína en dietas de gallinas ponedoras, siendo así el objetivo central de esta revisión bibliográfica.

Palabras clave: estrés calórico, grasas, producción de huevos

\section{Introdução}

Os custos com alimentação na avicultura de postura industrial representam cerca de $75 \%$ dos custos totais de produção. Esses valores, aproximadamente $85 \%$ correspondem aos níveis energéticos e proteicos da dieta. A grande variação nos preços ao longo dos anos dos principais ingredientes das rações, fez com que os nutricionistas buscassem alternativas de manipulação das dietas, evitando a queda no desempenho das aves.

O consumo de alimentos pelas aves é geralmente controlado pelo nível energético da ração e esta, deve conter todos os nutrientes necessários para as exigências de mantença e produção. Segundo Sibbald (1980), a relação entre a necessidade energética e o consumo de alimentos é o ponto fundamental da formulação prática de rações, uma vez que quando essa relação é pré-determinada, o consumo de nutrientes pode ser regulado.

Os níveis de energia e proteína das dietas de galinhas poedeiras variam bastante, entre 2.685 a $3.100 \mathrm{kcal}$ de $\mathrm{EM} / \mathrm{kg}$ e 14,5 a $19,0 \%$ de PB, respectivamente (Grobas et al., 1999). De acordo com NRC (1994), quando se altera a razão EM:PB da dieta, o consumo de proteína (aminoácidos) e de outros nutrientes pode ser afetado. Em virtude das rápidas mudanças no melhoramento genético das linhagens das aves, a realização de estudos periódicos com rações variando a razão EM:PB deve contribuir para detectar possíveis falhas nos programas de seleção e orientar eventuais correções nos planos de nutrição (Emmans, 1987).

Galinhas poedeiras em estresse por calor apresentam queda na produtividade e na qualidade dos ovos, principalmente na integridade da casca. Considerando que as aves reduzem voluntariamente o consumo de ração à medida que a temperatura ambiente se eleva acima da faixa de conforto térmico, uma ração baseada nas condições de termoneutralidade não seria adequada para atender as exigências energéticas das aves em ambiente de estresse por calor (Oliveira et al., 2000).

Dessa maneira, objetiva-se com esta revisão, abordar as principais respostas fisiológicas de galinhas poedeiras submetidas a diferentes condições climáticas, além de demonstrar os principais efeitos da manipulação da razão energia metabolizável:proteína bruta da dieta, sobre o desempenho produtivo e a qualidade dos ovos. 


\section{A homeostasia nas aves}

Mais de setenta por cento da massa corporal dos animais é composta por água e muitas das reações químicas que liberam energia ou que sintetizam novos compostos, ocorrem em um meio aquoso contendo uma complexa mistura de íons e outros solutos (Boschini et al., 2011). A temperatura é um fator crítico para a funcionalidade dos organismos, pois todas as reações bioquímicas são sensíveis a ela. Geralmente, as taxas de reações químicas aumentam à medida que a temperatura se eleva, mas nem todas as reações apresentam esta mesma sensibilidade (Pough et al., 2009).

As aves, por serem animais homeotermos, possuem habilidade para manter a temperatura corporal constante, pelo centro termorregulador localizado no hipotálamo, mediante a produção e liberação de calor no organismo para o ambiente (termogênese e termólise, respectivamente). No entanto, esse mecanismo de homeostase só é eficiente quando a temperatura ambiente se encontra em certos limites, denominados de zona crítica inferior e zona crítica superior. O intervalo entre essas faixas de temperatura é denominado de zona de conforto térmico, onde a eficiência produtiva dos animais é melhorada. Para aves adultas, a zona de conforto térmico situa-se entre 18 e $28^{\circ} \mathrm{C}$, já para as aves recém-nascidas a faixa de temperatura está situada entre 34 e $36^{\circ} \mathrm{C}$. Em situações que as aves estão submetidas, acima ou abaixo desses limites, várias respostas fisiológicas e comportamentais são desencadeadas, com a finalidade de manter a temperatura do núcleo corporal $\left(41^{\circ} \mathrm{C}\right)$ constante.

\section{Respostas fisiológicas e comportamentais de galinhas poedeiras submetidas ao estresse por frio}

O Brasil, país predominantemente tropical, registra temperaturas elevadas em boa parte do ano. Devido a este fato, os produtores de aves dão pouca atenção ao estresse pelo frio nas propriedades. Baixas temperaturas para aves, ou seja, abaixo da zona crítica inferior $\left(16\right.$ a $\left.18^{\circ} \mathrm{C}\right)$, podem comprometer o desempenho dos animais, provocando o aumento no consumo de alimentos para elevar a produção de calor metabólico e manter a homeotermia. Dessa forma, grande parte dos nutrientes ingeridos será direcionada para a mantença e uma pequena quantidade para o crescimento, elevando os requerimentos para a mantença. Segundo Albuquerque et al. (2011), em condições de extremo frio, se o animal é mantido em uma mesma dieta energética, constante para qualquer temperatura, a energia disponível para o seu crescimento é reduzida. Um dos principais mecanismos fisiológicos dos animais submetidas ao estresse pelo frio é a ativação do tecido adiposo marrom (TAM). Esse tecido é composto por células caracterizadas pela presença de várias gotículas lipídicas citoplasmáticas de diferentes tamanhos, apresentando um grande número de mitocôndrias. Essas mitocôndrias não possuem enzimas necessárias para a síntese de ATP, característica que habilita este tecido na utilização da energia liberada pela oxidação de metabólitos, principalmente ácidos graxos, para gerar calor, participando ativamente da regulação da temperatura corporal. Esse processo ocorre por mediação da proteína desacopladora-1 (UCP-1, termogenina). Uma proteína da membrana das mitocôndrias internas do adipócito marrom, que atua como um canal de próton que descarrega a energia gerada pelo acúmulo de prótons no espaço intermembranoso das mitocôndrias durante as reações oxidativas do ciclo de Krebs. Assim, desviando prótons e impedindo a síntese de ATP, permitindo que se dissipe em calor a energia estocada na mitocôndria (Cannon \& Nedergaard, 2004). Entretanto, de acordo com Macari et al. (2002), as aves são desprovidas de tecido adiposo marrom, que possui ação termogênica na maioria dos mamíferos. Dessa maneira, as galinhas poedeiras apresentam outras alterações fisiológicas quando submetidas ao estresse por frio. Uma das principais respostas fisiológicas observadas em galinhas poedeiras submetidas ao estresse por frio é o aumento da atividade da glândula tireoide, resultando em modificação da taxa metabólica dos animais e, consequentemente, da produção de calor. O estímulo ao aumento da secreção de tiroxina e a ativação da epinefrina e a norepinefrina, proporcionam maior oxidação dos alimentos no organismo, ocasionando numa maior produção de energia e incremento do metabolismo celular. Geralmente, a produção de hormônios da tireoide respondem às mudanças na demanda termogênica, imposta pelas alterações crônicas na temperatura ambiente. Temperaturas baixas aumentam a atividade do eixo da tireoide dos animais (Arancibia et al., 1996).

O plano nutricional utilizado influencia de forma significativa a produção de calor nos animais no estresse por frio, que é altamente correlacionada com $o$ peso dos órgãos metabolicamente ativos das aves, como o fígado, 
rins e coração. Uma das principais alterações fisiológicas provocadas pela adaptação dos animais ao estresse por frio é o aumento no tamanho dos órgãos, que pode alterar a exigência nutricional dos animais. Esse aumento no tamanho relativo dos órgãos, ocasionado pelas baixas temperaturas, constitui uma adaptação dos animais em função da maior demanda metabólica, resultante do aumento no consumo de alimentos que ocorre nesse ambiente (Albuquerque et al., 2011).

Além das respostas fisiológicas, os animais podem expressar comportamentos específicos com o intuito de manter a temperatura corporal constante, em situações de estresse por frio, dentre as quais se destacam, o agrupamento dos animais para minimizar a superfície de exposição corporal, afastam-se de locais com incidência de ventos, buscam fontes de calor nos galpões, e, persistindo a queda na temperatura ambiente, de forma involuntária, o animal poderá aumentar a atividade do músculo esquelético (tremor), proporcionando uma maior produção de calor (Albuquerque et al., 2011).

\section{Respostas fisiológicas e comportamentais de galinhas poedeiras submetidas ao estresse por calor}

As atuais linhagens de galinhas poedeiras são cada vez mais produtivas, graças ao avanço do melhoramento genético, aliado aos planos nutricionais aplicados. Entretanto, o metabolismo dessas aves ficou mais acelerado, e sua capacidade termorregulatória é ineficiente em condições de alta temperatura e umidade.

A susceptibilidade das aves ao estresse calórico aumenta à medida que o binômio envolvendo a temperatura ambiente e a umidade relativa do ar ultrapassa a zona de conforto térmico, dificultando assim a dissipação de calor, aumentando a temperatura interna da ave, com efeito negativo sobre o desempenho (Borges et al., 2003). Entre as principais alterações fisiológicas compensatórias das galinhas poedeiras expostas ao calor, destacam-se a vasodilatação periférica, resultando em um aumento na perda de calor não evaporativo. Além disso, na tentativa de aumentar a perda de calor, a ave aumenta a área superficial, mantendo as asas afastadas do corpo, eriçando as penas e intensificando a circulação periférica. A perda de calor não evaporativo pode ocorrer também com o aumento da produção de urina, desde que essa perda seja compensada pelo maior consumo de água (Borges et al., 2003). Um dos distúrbios metabólicos mais evidentes em poedeiras submetidas ao estresse por calor é a alcalose respiratória. Esse distúrbio é desencadeado devido ao aumento da frequência respiratória das aves em estresse por calor, gerando uma hiperventilação e redução dos níveis de dióxido de carbono $\left(\mathrm{CO}_{2}\right)$ no sangue. Esse fenômeno influencia o equilíbrio eletrolítico do organismo, resultando na produção de ovos pequenos e de casca fina (Carvalho, 2012), reduzindo a espessura da casca em aproximadamente $12 \%$ (Campos, 2000). Aliado a isto, o aumento no consumo de água provoca um aumento na excreção de íons bicarbonato $\left(\mathrm{HCO}_{3}{ }^{-}\right)$, que são elementos fundamentais para a formação do carbonato de cálcio $\left(\mathrm{CaCO}_{3}\right)$. Este último é o componente predominante da casca dos ovos, e seu déficit, provoca uma diminuição na qualidade da casca; sendo observada a produção de ovos de casca fina e/ou quebradiça, como pode ser observado na Figura 1.

$\mathrm{O}$ estresse pelo calor afeta o equilíbrio ácidobásico do organismo das aves, que é regulado principalmente pela ingestão dos minerais: sódio $\left(\mathrm{Na}^{+}\right)$, cloro $\left(\mathrm{Cl}^{-}\right)$e potássio $\left(\mathrm{K}^{+}\right)$. Esse desequilíbrio eletrolítico pode comprometer o bom funcionamento dos sistemas enzimáticos do organismo, além de afetar a condução e a transmissão neural e muscular (Silva et al., 2006a).

Outra resposta fisiológica observada em poedeiras em estresse por calor é a alteração do fluxo sanguíneo, que segue para as extremidades sem penas e outros tecidos das aves, como a língua, laringe e traqueia, aumentando a perda de calor por radiação, condução e convecção (Nolan et al., 1978). De acordo com Borges et al. (2003), o sistema sanguíneo dos animais é muito sensível às mudanças de temperatura do ambiente, principalmente ao estresse pelo calor, ocasionando alterações quantitativas e morfológicas nas células sanguíneas, seguidas de aumento nos valores do hematócrito (aumento no número de hemácias), modificação na razão heterófilo/linfócito (aumento de heterofilo e redução de linfócito), elevação da concentração de glicose em resposta à maior secreção de adrenalina, noradrenalina e glicocorticoides.

O estresse pelo calor, também afeta o sistema reprodutivo das aves. Segundo Miller \& Sunde (1975), as altas temperaturas ocasionam uma redução na secreção de FSH (hormônio folículo estimulante), que diminui o tamanho da gema. 
Aliado a isto, o baixo consumo de alimentos, além de menores deposições de aminoácidos ao magno e a baixa quantidade de cálcio disponível no útero, proporcionam a produção de ovos de tamanho reduzido e com pior qualidade de casca. Corroborando essas informações, Mack et al. (2013) afirmam que a redução na produção e qualidade dos ovos é mediada pela diminuição da disponibilidade dietética de cálcio e pela regressão de funções reprodutivas, causadas pelo menor consumo de alimentos no estresse por calor.
Ademais, as altas temperaturas ambientais modificam o perfil endócrino, indiretamente pela redução no consumo de ração e diretamente por alterar a síntese e secreção de hormônios reprodutivos, como o estradiol (Rozenboim et al., 2007, Elnagar et al., 2010) e a progesterona (Novero et al., 1991, Elnagar et al., 2010). Esses hormônios são exigidos para uma atividade reprodutiva normal e, consequentemente, a produção de ovos (Oguntunji \& Alabi, 2010).

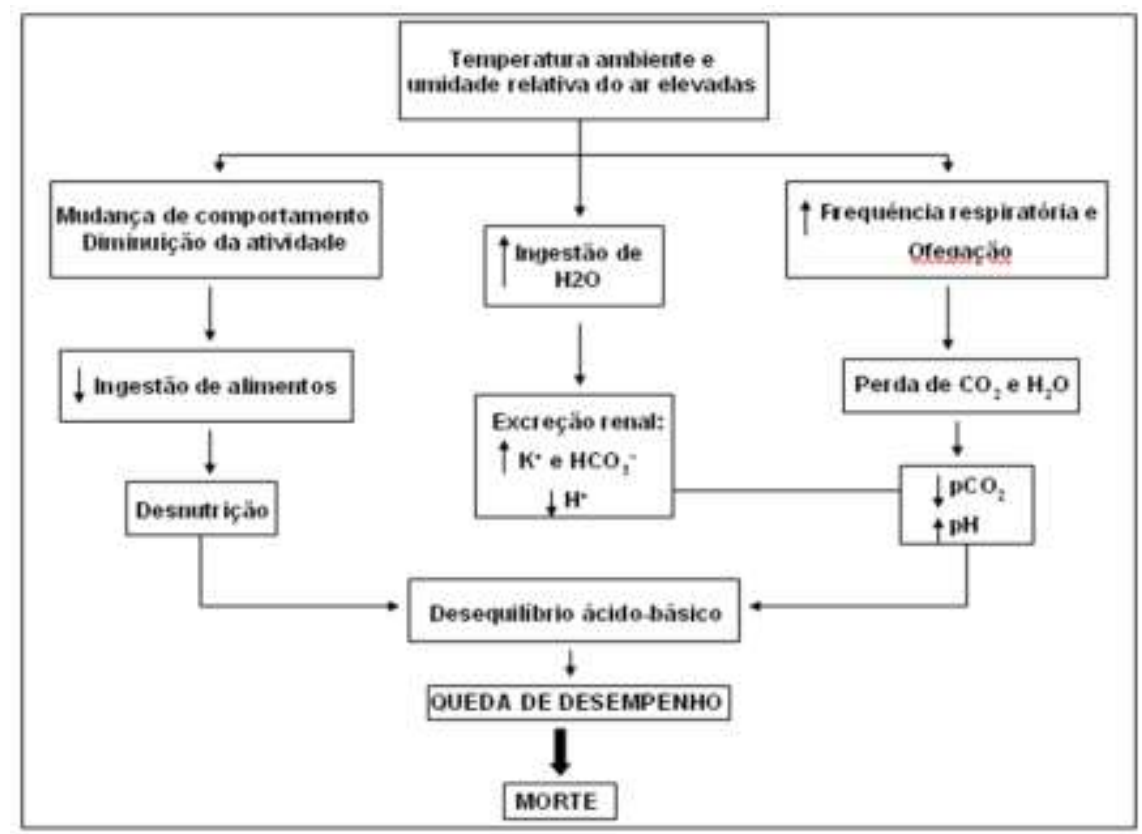

Figura 1. Resposta das aves ao estresse por calor (Adaptado de Borges et al., 2003).

Em situações de estresse pelo calor, as células, pelos ribossomos podem manifestar-se de diversas formas, destacando-se a resposta ao choque térmico, denominada de resposta ao estresse térmico (Welch, 1992). Essa alteração permite a expressão de uma classe de proteínas, conhecidas como HSPs (heat shock proteins) (Locke \& Noble, 1995, Fehrenbach \& Niess, 1999) que são essenciais para a sobrevivência de células expostas a um agente ambiental estressante (Welch, 1992). As HSPs mantêm as proteínas recém-sintetizadas em uma conformação que favorece sua translocação, auxilia a sua ligação a proteínas não-ativas durante o estresse celular (Fink, 1999), auxilia no transporte de proteínas pelas membranas mitocondriais e a interação com receptores de esteroides. Dentre as principais HSPs, diferenciando seus pesos moleculares, destacam-se as proteínas 60, 70, 90 e $110 \mathrm{Kda}$, sendo denominadas HSPs principais (Kiang \& Tsokos, 1998). Dessa forma, estudos sobre a HSP 70 e seus efeitos sobre o organismo, demonstram que a aquisição de termotolerância, está relacionada com aumento dos níveis dessa proteína (Parsell \& Lindquist, 1994), e, por isso, são denominadas de chaperonas moleculares. Essas proteínas utilizam energia da hidrólise de ATP para desnovelar proteínas, possibilitando um novo enovelamento, dessa vez na forma correta ou no lugar correto. Ademais, as chaperonas agem reparando os danos causados pelas falhas de dobramento, além de participarem no dobramento de novas proteínas que deixam o ribossomo (Mayer \& Bukau, 2005).

De acordo com Boschini et al. (2011), a exposição dos animais ao estresse pelo calor no início da vida permite que o gene que regula a síntese da HSP 70 seja estimulado, favorecendo uma rápida expressão e síntese desta proteína em situações de estresse térmico, tornando o animal termorresistente à temperaturas elevadas.

Além das respostas fisiológicas, as galinhas poedeiras podem apresentar comportamentos 
específicos quando submetidas ao estresse por calor. Dentre os principais comportamentos destacam-se, o eriçamento das penas, o afastamento das asas, na tentativa de aumentar a área de superfície, buscam locais mais ventilados e/ou mais frescos, além de aumentarem o consumo de água (resfriamento não evaporativo) e reduzirem o consumo de alimentos.

\section{Níveis de energia metabolizável e adição de fontes de gordura na dieta de galinhas poedeiras em estresse por calor}

Segundo Sakomura et al. (2004), uma das áreas a ser explorada é o estudo do crescimento e do metabolismo energético das aves, envolvendo os fatores que os afetam, assim como o aproveitamento dos demais nutrientes da dieta, facilitando, a manipulação das rações com o objetivo de melhorar as características de carcaça, com maior deposição de proteína e diminuindo o acúmulo de gordura.

O calor gerado pelos processos metabólicos e o recebido pelo ambiente devem ser dissipados do corpo da ave para o meio, com a finalidade que a homeotermia seja mantida, com gasto mínimo de energia em ambiente termoneutro. No entanto, quando submetidas a altas temperaturas, acima da zona de conforto térmico, as aves apresentam maior dificuldade em manter a sua temperatura corporal, já que não possuem glândulas sudoríparas e a camada isolante da cobertura de penas dificulta a troca de calor com o meio (Oliveira Neto et al., 2000b).

Segundo Cheng et al. (1997), grande parte da redução do desempenho de aves criadas em altas temperaturas, quando comparado com aves em condições termoneutras, é ocasionado pelas diferenças no consumo de energia e de aminoácidos. $\mathrm{O}$ menor consumo de ração observado em aves mantidas em estresse pelo calor é uma tentativa de reduzir a taxa de calor metabólico. Em reflexo disso, ocorre piora no ganho de peso e na conversão alimentar.

Em situações de estresse por calor, segundo Leeson et al. (1996), a inclusão de óleo vegetal nas rações de aves reduz os efeitos negativos da temperatura sobre o desempenho. $\mathrm{O}$ efeito benéfico da adição de fontes de óleo nas rações de aves submetidos a altas temperaturas está associado às modificações na fisiologia gastrointestinal e ao menor incremento calórico da dieta verificado durante os processos de digestão, absorção e assimilação dos nutrientes das rações contendo maior teor de óleo. Esse efeito da fonte lipídica da ração sobre a partição de energia resulta em maior quantidade de energia líquida utilizada para a produção (Oliveira Neto et al., 2000a).

Estudos realizados nas décadas de 70 e 80, já demonstravam que a redução do calor metabólico a partir da gordura dietética (fontes de óleo), quando comparada com outras fontes de energia, tem demonstrado aos nutricionistas um aumento no desempenho de frangos de corte alimentados com dietas de alta energia em condições de altas temperaturas (Olson et al., 1972, Reece \& McNaughton, 1982). Mesmo apresentando redução no consumo de alimentos, a partir do aumento do nível energético da dieta com a adição de fontes de gordura, o consumo real de energia é elevado, graças ao menor incremento de calor gerado no organismo. Os efeitos da suplementação com fontes de óleo na ração de frangos de corte submetidos ao estresse por calor já é bem conhecido, principalmente em relação à eficiência da deposição de proteína e gordura na carcaça (Oliveira Neto et al., 2000a, Oliveira Neto et al., 2000b). No entanto, os estudos ainda são escassos quanto à suplementação com níveis de fontes de óleo sobre o desempenho e a qualidade dos ovos de galinhas poedeiras em situações de estresse por calor. Várias pesquisas têm relatado que o aumento do nível de energia pela adição de óleo de milho ou de aves aumenta o peso dos ovos, com poedeiras criadas em ambientes termoneutros (Keshavarz, 1995, Keshavarz \& Nakajima, 1995, Harms et al., 2000, Bohnsack et al., 2002, Sohail et al., 2003). A literatura é muito limitada sobre o efeito da energia dietética sobre o desempenho, a composição, os sólidos e a qualidade dos ovos, principalmente em situações de estresse por calor.

Wu et al. (2005) avaliaram níveis de energia metabolizável (2.719, 2.798, 2.877 e $2.959 \mathrm{kcal}$ de $\mathrm{EM} / \mathrm{kg}$ sobre a qualidade dos ovos de duas linhagens de poedeiras (Bovans White e Dekalb White) e relataram que o aumento da energia dietética proporcionou uma redução no consumo de alimentos $(107,6 \mathrm{~g}$ para $101,1 \mathrm{~g}$ de ração por dia. O aumento de $39 \mathrm{kcal}$ de $\mathrm{EM} / \mathrm{kg}$ diminuiu o consumo de ração em $1 \%$ ), aumentou o peso dos ovos (maior conteúdo da gema) e melhorou a conversão alimentar. Esses resultados são semelhantes aos encontrados por Grobas et al. (1999), que observaram que o aumento de $33 \mathrm{kcal}$ de $\mathrm{Em} / \mathrm{kg}$ na dieta de poedeiras diminuiu o consumo de ração em 1\%. Mais recentemente, em estudo semelhante, Gunawardana et al. (2009) 
avaliaram quatro níveis de energia metabolizável $(2.791,2.857,2.923$ e $2.989 \mathrm{kcal}$ de $\mathrm{EM} / \mathrm{kg}) \mathrm{na}$ dieta de poedeiras Hy-Line W-36, e também observaram redução no consumo de ração (98 a $94,9 \mathrm{~g}$ de ração por dia), além de observarem um aumento na coloração da gema (5.27 a 5.56). No entanto, em situações de estresse por calor, a manipulação da energia da dieta de galinhas poedeiras deve seguir alguns procedimentos, conforme Grieve (2003).

- De uma forma geral, para cada aumento de $2,5^{\circ} \mathrm{C}$ na temperatura ambiente no galpão, a partir de $29^{\circ} \mathrm{C}$, o conteúdo de energia da dieta deverá ser reduzido em $22 \mathrm{kcal} / \mathrm{kg}$. O conteúdo de energia da alimentação deve ser reduzido devido à grande parte da exigência energética da ave, ser atendida pelo aumento da temperatura ambiente.

- À medida que a quantidade total de energia da ração é reduzida, a proporção de energia total da ração pela adição de fontes de gordura deve ser aumentada. A adição de fontes de gordura na dieta, em alguns casos, pode ser superior a 4,5\% da ração;

- Um subproduto da digestão $\mathrm{E}$ metabolismo do alimento é a produção de calor corporal (incremento calórico). Já é bem reconhecido que o incremento calórico das fontes de gordura é inferior aos outros nutrientes, como a proteína e os carboidratos. A digestão da gordura resulta numa menor produção de calor corporal por caloria de energia do alimento. Dessa maneira, a carga térmica da ave pode ser reduzida através da substituição de parte da energia da dieta, por fontes de gordura.

\section{Níveis de proteína bruta e suplementação com aminoácidos sintéticos para galinhas poedeiras em estresse por calor}

A proteína é o nutriente responsável pelo maior incremento calórico da dieta, sendo superior aos carboidratos e a gordura, devido à grande quantidade de passos metabólicos nos processos de digestão, absorção e metabolismo desse composto. Em situações de estresse por calor, a redução da proteína bruta e suplementação com aminoácidos sintéticos, também surge como uma alternativa para amenizar os efeitos do estresse por calor e melhorar o desempenho e a qualidade dos ovos de galinhas poedeiras.

O conceito de proteína ideal pode ser entendido como um total de aminoácidos na quantidade e proporções exatas para atender os requerimentos de mfigantença e alta deposição de proteína na carcaça. De acordo com este conceito, todos os aminoácidos são proporcionalmente limitantes para o desempenho dos animais e, por esse motivo, a redução de qualquer aminoácido, independentemente do nível, pode ocasionar a sua deficiência (Furlan et al., 2004). Dessa maneira, vários estudos têm comprovado que excessos de proteína bruta na ração podem aumentar o calor metabólico e reduzir o desempenho das aves, além de aumentar a excreção de nitrogênio (Waldroup et al., 1976, Cheng et al., 1997, Aletor et al., 2000). Aliado a isso, rações com elevado teor de proteína bruta, formuladas para suprir as exigências de aminoácidos das aves, fornecem quantidades desse nutriente superiores aos requerimentos, ocasionando o excesso de aminoácidos circulantes, que, ao serem metabolizados, aumentam a produção de calor corporal (Silva et al., 2006b).

Estudos anteriores já demonstravam que o aumento das concentrações de aminoácidos pode melhorar o desempenho de aves criadas em ambientes de alta temperatura. O estresse por calor reduz o consumo da proteína dietética, e a suplementação com aminoácidos industriais, graças ao seu melhor aproveitamento pelas aves, pode melhorar a utilização da proteína e, consequentemente, a produtividade e qualidade dos ovos de poedeiras.

De acordo com Grieve (2003), quando a densidade de nutrientes da formulação é aumentada, para compensar a redução da ingestão de alimentos em situações de estresse por calor, o teor de proteína bruta da ração, em alguns casos, pode ser reduzido em cerca de $0,50 \%$. Caso isto seja realizado, a ingestão de aminoácidos essenciais pode ser otimizada pela suplementação de quantidades crescentes de aminoácidos sintéticos, principalmente a metionina e lisina.

No entanto, várias pesquisas vêm sendo desenvolvidas com o intuito de avaliar o desempenho de aves submetidas a condições de estresse por calor e alimentadas com dietas de alta proteína bruta (Furlan et al., 2004). Temim et al. (1999) demonstraram que a alimentação de frangos de corte com dietas de alta proteína bruta (25 vs. 20\%) em alta temperatura $\left(32^{\circ} \mathrm{C}\right)$, durante o período de crescimento, aumentou o ganho de peso e melhorou a conversão alimentar, conforme Tabela 1. 
Tabela 1. Consumo de ração, ganho de peso e conversão alimentar de frangos de corte submetidos a temperatura termoneutra $\left(22^{\circ} \mathrm{C}\right)$ ou estresse por calor $\left(32^{\circ} \mathrm{C}\right)$ alimentados com dietas de baixa ou alta proteína bruta $(20 \mathrm{vs} 25 \%)$.

\begin{tabular}{lcccc}
\hline \multirow{2}{*}{ Variáveis } & \multicolumn{2}{c}{ Termoneutralidade } & \multicolumn{2}{c}{ Estresse por calor } \\
\cline { 2 - 4 } & $20 \% \mathrm{~PB}$ & $25 \% \mathrm{~PB}$ & $20 \% \mathrm{~PB}$ & $25 \% \mathrm{~PB}$ \\
\hline Consumo de ração (g/dia) & $162 \mathrm{a}$ & $157 \mathrm{a}$ & $115 \mathrm{~b}$ & $122 \mathrm{~b}$ \\
Ganho de peso (g/dia) & $87,2 \mathrm{a}$ & $89,7 \mathrm{a}$ & $47,1 \mathrm{c}$ & $54,3 \mathrm{~b}$ \\
Conversão alimentar & $1,86 \mathrm{a}$ & $1,76 \mathrm{~d}$ & $2,52 \mathrm{a}$ & $2,35 \mathrm{~b}$ \\
\hline
\end{tabular}

Adaptado de Temim et al. (1999)

Da mesma forma, Geraert et al. (1993) observaram que dietas com alta proteína bruta $(23$ vs. $19 \%$ ) foi capaz de reduzir a produção de calor em frangos submetidos ao estresse por calor $\left(32^{\circ}\right.$ C), entre a terceira e a nona semana de idade. Em pesquisa semelhante, Zarate et al. (2003) avaliaram um dieta comercial, com ou sem suplementação de aminoácidos essenciais, em frangos de corte durante o verão e concluíram que a suplementação com aminoácidos teve um efeito mínimo sobre a produção de calor, com uma maior utilização de energia para deposição de gordura, do que para a síntese proteica.

No entanto, dietas com alta proteína aumentam a excreção de nitrogênio para o ambiente, e, segundo Furlan et al. (2004), três itens básicos precisam ser considerados para definir um melhor nível de proteína dietética para aves em estresse por calor: a produtividade, a qualidade do produto final e impacto ambiental (excreção de nitrogênio).

\section{Razão energia metabolizável e proteína bruta para galinhas poedeiras em estresse por calor}

A razão entre energia e proteína das dietas de galinhas poedeiras mantidas em estresse por calor também pode afetar o desempenho e qualidade dos ovos. No entanto, os relatos também são escassos na literatura. Segundo Emmans (1987), em virtude das rápidas mudanças no melhoramento genético das linhagens das aves, a realização de estudos periódicos com rações variando a razão energia:proteína deve contribuir para detectar possíveis falhas nos programas de seleção, em relação à qualidade da carcaça, e orientar eventuais correções nos planos de nutrição, com a finalidade de evitar o excesso de gordura na carcaça.

De acordo com Silva et al. (2001), em grande parte dos estudos, as relações proteína e outros nutrientes importantes da dieta, como lisina, metionina+cistina, não foram mantidas, à medida que as relações caloria:proteína foram determinadas, o que podo comprometer o desempenho dos animais, em virtude de possíveis interações entre os diferentes nutrientes da ração. A relação energia:proteína proporciona diversas implicações nas dietas de aves como a quantidade de gordura suplementar, custo da ração, taxa de crescimento, conversão alimentar e composição corporal (Pesti, 1999), além das interações com a genética e o ambiente das aves, sendo este último, o fator mais importante (Silva et al., 2001).

Os efeitos da razão energia:proteína sobre o desempenho e qualidade de carcaça de frangos de corte em estresse por calor, vêm sendo avaliado nos últimos anos. Silva et al. (2001) avaliaram os efeitos da relação energia:proteína na dieta de frangos de corte em ambiente com temperatura de $26^{\circ} \mathrm{C}$ e observaram que o aumento da relação energia:proteína apresentou efeito linear decrescente sobre o consumo de ração, ganho de peso, consumo de proteína, consumo de energia metabolizável, peso da carcaça, peso do peito, peso de pernas (coxa + sobrecoxa), além de elevar a porcentagem de gordura abdominal na carcaça. Os autores atribuíram esses resultados ao menor conteúdo de proteína, a partir do aumento das razões energia:proteína. Prak (1999) afirma que as linhagens atuais de aves exigem menores razões de energia:proteína, a fim de atingir o máximo ganho e melhor conversão alimentar.

Oliveira Neto et al. (2000b) avaliaram os efeitos do estresse pelo calor sobre o desempenho e características de carcaça de frangos de corte alimentados com dois níveis de energia metabolizável (3.075 e $3.300 \mathrm{kcal}$ de EM/kg e razão energia:proteína de 137 e 147) e observaram que as altas temperaturas influenciaram negativamente $o$ desempenho, reduziu $o$ rendimento de peito e o peso dos órgãos vitais, além de aumentar a gordura abdominal, independente do nível energético e da relação energia:proteína da ração.

Em dietas isoenergéticas, quando os níveis de proteína bruta são reduzidos, ocorre um aumento da razão energia:proteína, que favorece a uma maior deposição de gordura corporal nas aves 
(Leeson et al., 1996). Nesse sentido, mais recentemente, Oliveira et al. (2010) avaliaram a redução proteica em rações de frangos de corte em ambientes de estresse por calor $\left(32,2^{\circ} \mathrm{C}\right.$ e ITGU 83 , com relação energia metabolizável e proteína bruta variando entre 143 a 175). Os autores não observaram efeitos sobre o ganho de peso, consumo de ração, conversão alimentar e características de carcaça.

Como comentado anteriormente, os estudos avaliando os efeitos da razão energia:proteína para galinhas poedeiras ainda são escassos, principalmente em situações de estresse por calor. Segundo Rostagno et al. (2005), a razão energia metabolizável e proteína bruta é de 181 para galinhas com 1,5 kg de peso corporal, de 177 para aves com $1,6 \mathrm{~kg}$ de peso corporal e de 174 para poedeiras com 1,65 kg de peso corporal.

Costa et al. (2004) avaliaram os níveis de proteína bruta e energia metabolizável (razão energia:proteína variando entre 174 à 187) sobre a produção e qualidade dos ovos de poedeiras semipesadas no nordeste brasileiro. Esses autores observaram que os níveis avaliados não influenciaram significativamente nenhum dos parâmetros avaliados, exceto para a porcentagem do albúmen e da casca. Em pesquisa semelhante, Lima Neto (2006) avaliou os efeitos dos níveis de energia metabolizável e proteína bruta para aves de reposição (1 a 18 semanas de idade), não sendo observada nenhuma resposta para as variáveis avaliadas no estudo. Mais recentemente, Rama $\underline{\text { Rao et al. (2011) avaliaram os efeitos das }}$ concentrações dietéticas de energia metabolizável, proteína bruta, lisina e metionina sobre o desempenho de poedeiras leves submetidas ao estresse por calor $\left(35,5^{\circ} \mathrm{C}\right)$. No primeiro ensaio, os autores avaliaram os níveis de energia metabolizável (2.350 e $2600 \mathrm{kcal}$ de EM/kg) e proteína bruta $(15,16,5$ e $18 \%$ de $\mathrm{PB})$ e recomendaram a utilização de dietas com $15 \%$ de proteína bruta e $2600 \mathrm{kcal}$ de EM/kg, com razão energia:proteína de aproximadamente 173, para uma melhor produção de ovos em condições tropicais. Já no segundo e terceiros experimentos, os autores avaliaram a suplementação da dieta com lisina $(0,65 ; 0,70 ; 0,75$ e $0,80 \%)$ e metionina $(0,305 ; 0,335 ; 0,355$ e $0,395 \%)$, respectivamente. Os autores recomendaram o nível de aproximadamente $0,70 \%$ de lisina e o nível mais baixo de metionina avaliado nas dietas.

\section{Níveis de energia metabolizável e proteína bruta para galinhas poedeiras em estresse por frio}

Galinhas poedeiras em estresse por frio aumentam o consumo de alimentos na tentativa de natural de elevar a ingestão de energia necessária a manutenção das atividades vitais, como a homeotermia. Dessa maneira, grande parte da energia consumida será direcionada para a manutenção da temperatura corporal e uma menor parte será utilizada para o crescimento. No entanto, segundo Pereira (2005), se a temperatura ambiente diminui ainda mais, uma parte dos nutrientes é catabolizada como reserva de calor em detrimento da produção, não sendo suficiente o aumento no consumo de ração.

De acordo com Haese \& Bünzen (2005), em ambientes frios o nível de energia da dieta deve ser maior (deve-se evitar o uso de gorduras, devido ao baixo incremento calórico), para que não ocorra uma mobilização de proteínas da dieta para a produção de calor metabólico. Esses autores também afirmam que a razão energia:proteína da dieta deverá ser mais estreita em situações de estresse por frio, uma vez que, havendo ligeira sobra de proteína, esta será direcionada para o metabolismo energético, pelo processo de desaminação, aumentando o incremento calórico da dieta, sem ocasionar prejuízos ao desempenho dos animais.

Outra alternativa nutricional para poedeiras em situações de frio é a utilização de alimentos fibrosos. Segundo Curtis (1983) a utilização de alimentos ricos em fibra na ração aumenta o incremento calórico, auxiliando na termogênese. Ademais, o consumo voluntário da ração está inversamente relacionado ao conteúdo da fibra, sendo que uma ração com um conteúdo de fibra mais alto aumenta o incremento calórico e, dependendo da qualidade da fibra, o consumo de ração pode ser limitado pela capacidade do estômago.

\section{Referências Bibliográficas}

Albuquerque, R., Araújo, C. S. S., Araújo, L. F., Ferreira, N. T. \& Burbarelli, F. C. 2011. Cuidados com a alimentação avícola no tempo frio. Acesso em: 02/02/2013.

Aletor, V. A., Hamid, I. I., Niess, E. \& Pfeffer, E. 2000. Low-protein amino acid-supplemented diets in broiler chickens: effects on performance, carcass characteristics, wholebody composition and efficiencies of nutrient 
utilisation. Journal of the Science of Food and Agriculture, 80, 547-554.

Arancibia, S., Rage, F., Astier, H. \& TapiaArancibia, L. 1996. Neuroendocrine and autonomous mechanisms underlying thermoregulation in cold environment. Neuroendocrinology, 64, 257-267.

Bohnsack, C. R., Harms, R. H., Merkel, W. D. \& Russell, G. B. 2002. Performance of commercial layers when fed diets with four levels of corn oil or poultry fat. Journal of Applied Poultry Research, 11, 68-76.

Borges, S. A., Maiorka, A. \& Silva, A. V. F. 2003. Fisiologia do estresse calórico e a utilização de eletrólitos em frangos de corte. Ciência Rural, 33, 975-981.

Boschini, C., Gonçalves, F. M., Catalan, A. A. S., Bavaresco, C., Gentilini, F. P., Anciuti, M. A. \& Dionello, N. J. L. 2011. Relação entre a proteína de choque térmico e o estresse térmico em frango de corte. Archivo de Zootecnia, 60, 63-77.

Campos, E. J. 2000. Avicultura: razões, fatos e divergências. FEP-MVZ, Belo Horizonte, Minas Gerais.

Cannon, B. \& Nedergaard, J. A. N. 2004. Brown adipose tissue: function and physiological significance. Physiological Reviews, 84, 277359.

Carvalho, L. S. S. 2012. Nutrição de poedeiras em clima quente. Revista Científica Eletrônica de Medicina Veterinária, 18, 1-15.

Cheng, T. K., Hamre, M. L. \& Coon, C. N. 1997. Effect of environmental temperature, dietary protein, and energy levels on broiler performance. Journal of Applied Poultry Research, 6, 1-17.

Costa, F. G. P., Souza, H. C., Gomes, C. A. V., Barros, L. R., Brandão, P. A., Nascimento, G. A. J., Santos, A. W. R. \& Amarante Junior, V. S. 2004. Níveis de proteína bruta e energia metabolizável na produção e qualidade dos ovos de poedeiras da linhagem Lohmann Brown. Ciência Agrotécnica, 28, 1421-1427.

Curtis, S. E. 1983. Environmental management in animal agriculture. Iowa State University Press, Iowa, USA.

Elnagar, S. A., Scheideler, S. E. \& Beck, M. M. 2010. Reproductive hormones, hepatic deiodinase messenger ribonucleic acid, and vasoactive intestinal polypeptideimmunoreactive cells in hypothalamus in the heat stress-induced or chemically induced hypothyroid laying hen 12 . Poultry Science, 89, 2001-2009.

Emmans, G. C. 1987. Growth, body composition and feed intake. World's Poultry Science Journal, 43, 208-227.

Fehrenbach, E. \& Niess, A. M. 1999. Role of heat shock proteins in the exercise response. Exercise Immunology Review, 5, 57-77.

Fink, A. L. 1999. Chaperone-mediated protein folding. Physiological Reviews, 79, 425-449.

Furlan, R. L., Faria Filho, D. E., Rosa, P. S. \& Macari, M. 2004. Does low-protein diet improve broiler performance under heat stress conditions? Revista Brasileira de Ciência Avícola, 6, 71-79.

Geraert, P. A., Guillaumin, S. \& Leclercq, B. 1993. Are genetically lean broilers more resistant to hot climate? British Poultry Science, 34, 643-653.

Grieve, D. 2003. Heat Stress in Commercial Layers and Breeders., vol. 19, Iowa HLST, Technical Bulletin Hy-Line International.

Grobas, S., Mendez, J., De Blas, C. \& Mateos, G. G. 1999. Laying hen productivity as affected by energy, supplemental fat, and linoleic acid concentration of the diet. Poultry Science, 78, 1542-1551.

Gunawardana, P., Roland, D. A. \& Bryant, M. M. 2009. Effect of dietary energy, protein, and a versatile enzyme on hen performance, egg solids, egg composition, and egg quality of HyLine W-36 hens during second cycle, phase two. Journal of Applied Poultry Research, 18, 43-53.

Haese, D. \& Bünzen, S. 2005. Temperatura ambiental efetiva e consumo voluntário. Revista Eletrônica Nutritime, 2, 172-175.

Harms, R. H., Russell, G. B. \& Sloan, D. R. 2000. Performance of four strains of commercial layers with major changes in dietary energy. Journal of Applied Poultry Research, 9, 535541.

Keshavarz, K. 1995. Further investigations on the effect of dietary manipulations of nutrients on early egg weight. Poultry Science, 74, 62-74.

Keshavarz, K. \& Nakajima, S. 1995. The effect of dietary manipulations of energy, protein, and fat during the growing and laying periods on early egg weight and egg components. Poultry Science, 74, 50-61. 
Kiang, J. G. \& Tsokos, G. C. 1998. Heat shock protein $70 \mathrm{kDa}$ : molecular biology, biochemistry, and physiology. Pharmacology \& Therapeutics, 80, 183-201.

Leeson, S., Caston, L. \& Summers, J. D. 1996. Broiler response to diet energy. Poultry Science, 75, 529-535.

Lima Neto, R. C. 2006. Níveis de proteína bruta e energia metabolizável para aves de reposição e no início de postura. Centro de Ciências Agrárias. Universidade Federal da Paraíba, Areia, Paraíba.

Locke, M. \& Noble, E. G. 1995. Stress proteins: the exercise response. Canadian Journal of Applied Physiology, 20, 155-167.

Macari, M., Furlan, R. L. \& Gonzales, E. 2002. Fisiologia aviária aplicada a frangos de corte. Funep, Jaboticabal.

Mack, L. A., Felver-Gant, J. N., Dennis, R. L. \& Cheng, H. W. 2013. Genetic variations alter production and behavioral responses following heat stress in 2 strains of laying hens. Poultry Science, 92, 285-294.

Mayer, M. P. \& Bukau, B. 2005. Hsp70 chaperones: cellular functions and molecular mechanism. Cellular and Molecular Life Sciences, 62, 670-684.

Miller, P. C. \& Sunde, M. L. 1975. The effects of precise constant and cyclic environments on shell quality and other lay performance factors with Leghorn pullets. Poultry Science, 54, 3646.

Nolan, W. F., Weathers, W. W. \& Sturkie, P. D. 1978. Thermally induced peripheral blood flow changes in chickens. Journal of Applied Physiology, 44, 81-84.

Novero, R. P., Beck, M. M., Gleaves, E. W., Johnson, A. L. \& Deshazer, J. A. 1991. Plasma Progesterone, Luteinizing Hormone Concentrations, and Granulosa Cell Responsiveness in Heat-Stressed Hens. Poultry Science, 70, 2335-2339.

NRC. 1994. Nutrients Requirements of Poultry, 7th rev. edn. Natl. Acad. Press, Washington, DC., Washington.

Oguntunji, A. O. \& Alabi, O. M. 2010. Influence of high environmental temperature on egg production and shell quality: a review. World's Poultry Science Journal, 66, 739-750.

Oliveira Neto, A. R., Oliveira, R. F. M., Donzele, J. L., Rostagno, H. S., Ferreira, R. A. \& Carmo, H. M. 2000a. Níveis de energia metabolizável para frangos de corte no período de 22 a 42 dias de idade mantidos em ambiente termoneutro. Revista Brasileira de Zootecnia, 29, 11321140.

Oliveira Neto, A. R., Oliveira, R. F. M., Donzele, J. L., Rostagno, H. S., Ferreira, R. A., Maximiano, H. C. \& Gasparino, E. 2000b. Efeito da temperatura ambiente sobre o desempenho e características de carcaça de frangos de corte alimentados com dieta controlada e dois níveis de energia metabolizável. Revista Brasileira de Zootecnia, 29, 183-190.

Oliveira, R. F. M., Zanusso, J. T., Donzele, J. L., Ferreira, R. A., Albino, L. F. T., Valerio, S. R., Oliveira Neto, A. R. \& Carmo, H. M. 2000. Níveis de energia metabolizável para frangos de corte de 1 a 21 dias de idade mantidos em ambiente de alta temperatura. Revista Brasileira de Zootecnia, 29, 810-816.

Oliveira, W. P., Oliveira, R. F. M., Donzele, J. L., Gomes, P. C., Martins, M. d. S. \& Assis, A. P. 2010. Reduction of dietary crude protein level for broilers maintained in heat stressing environment. Revista Brasileira de Zootecnia, 39, 1092-1098.

Olson, D. W., Sunde, M. L. \& Bird, H. R. 1972. The effect of temperature on metabolizable energy determination and utilization by the growing chick. Poultry Science, 51, 19151922.

Parsell, D. A. \& Lindquist, S. 1994. Heat shock proteins and stress tolerance. In: Morimoto, R. I., Tissières, A. \& Georgopoulos, C. (eds.) The biology of heat shock proteins and molecular chaperones. Cold Spring Harbor Laboratory Press, New York.

Pereira, J. 2005. Fundamentos de bioclimatologia aplicados à produção animal. FEPMVZ, Belo Horizonte.

Pesti, G. M. 1999. Proteína (aminoácidos) para frangos. Simpósio Internacional Sobre Nutrição de Aves. Facta, Campinas, São Paulo.

Pough, F. H., Janis, C. M. \& Heiser, J. B. 2009. Hoemostase e energia: equilíbrio de água, regulação da temperatura e uso de energia. Editora Atheneu, São Paulo.

Prak, R. 1999. Chickens need more protein. World Poult, 15, 17.

Rama Rao, S. V., Ravindran, V., Srilatha, T., Panda, A. K. \& Raju, M. V. L. N. 2011. Effect of dietary concentrations of energy, crude 
protein, lysine, and methionine on the performance of White Leghorn layers in the tropics. Journal of Applied Poultry Research, 20, 528-541.

Reece, F. N. \& McNaughton, J. L. 1982. Effects of dietary nutrient density on broiler performance at low and moderate environmental temperatures. Poultry Science, 61, 2208-2211.

Rostagno, H. S., Albino, L. F. T., Donzele, J. L., Gomes, P. C., Oliveira, R., Lopes, D. C., Ferreira, A. S., Barreto, S. \& Euclides, R. F. 2005. Composição de alimentos e exigências nutricionais, 2 edn. Universidade Federal de Viçosa, Viçosa.

Rozenboim, I., Tako, E., Gal-Garber, O., Proudman, J. A. \& Uni, Z. 2007. The effect of heat stress on ovarian function of laying hens. Poultry Science, 86, 1760-1765.

Sakomura, N. K., Longo, F. A., Bôa-Viagem, C., Watanabe, K., Pelícia, K. \& Freitas, E. R. 2004. Efeito do nível de energia metabolizável da dieta no desempenho e metabolismo energético de frangos de corte. Revista Brasileira de Zootecnia, 33, 1758-1767.

Sibbald, I. R. 1980. The effects of dietary cellulose and sand on the combined metabolic plus endogenous energy and amino acid outputs of adult cockerels. Poultry Science, 59, 836-844.

Silva, J. D. B., Fuentes, M. F. F., Rodrigues Freitas, E., Espíndola, G. B., Sousa, F. M. \& Cruz, C. E. B. 2006a. Níveis de sódio em rações de pintos de corte na fase inicial. Revista Ciência Agronômica, 37.

Silva, J. H. V., Albino, L. F. T. \& Nascimento, A. H. 2001. Níveis de Energia e Relações Energia: Proteína para Frangos de Corte de 22 a 42 dias de Idade. Revista Brasileira de Zootecnia, 30, 1791-1800.

Silva, Y. L., Rodrigues, P. B., Freitas, R. T. F., Bertechini, A. G., Fialho, E. T., Fassani, E. J. \& Pereira, C. R. 2006b. Redução de proteína e fósforo em rações com fitase para frangos de corte no período de 1 a 21 dias de idade. Desempenho e teores de minerais na cama. Revista Brasileira de Zootecnia, 35, 840-848.

Sohail, S. S., Bryant, M. M. \& Roland, D. A. 2003. Influence of dietary fat on economic returns of commercial Leghorns. Journal of Applied Poultry Research, 12, 356-361.

Temim, S., Chagneau, A.-M., Guillaumin, S., Michel, J., Peresson, R., Geraert, P.-A. \& Tesseraud, S. 1999. Effects of chronic heat exposure and protein intake on growth performance, nitrogen retention and muscle development in broiler chickens. Reproduction Nutrition Development, 39, 145-156.

Waldroup, P. W., Mitchell, R. J., Payne, J. R. \& Hazen, K. R. 1976. Performance of chicks fed diets formulated to minimize excess levels of essential amino acids. Poultry Science, 55, 243-253.

Welch, W. J. 1992. Mammalian stress response: cell physiology, structure/function of stress proteins, and implications for medicine and disease. Physiological Reviews, 72, 10631081.

Wu, G., Bryant, M. M., Voitle, R. A. \& Roland, D. A. 2005. Performance comparison and nutritional requirements of five commercial layer strains in phase. International Journal of Poultry Science, 4, 182-186.

Zarate, A. J., Moran Junior, E. T. \& Burnham, D. J. 2003. Exceeding essential amino acid requirements and improving their balance as a means to minimize heat stress in broilers. Journal of Applied Poultry Research, 12, 3744.

Article History:

Received 28 September 2017

Accepted 27 October 2017

Available online 1 December 2017

License information: This is an open-access article distributed under the terms of the Creative Commons Attribution License 4.0, which permits unrestricted use, distribution, and reproduction in any medium, provided the original work is properly cited. 